\title{
ELECTRON BEAM TRANSVERSION MANAGEMENT ON EXIT OF MAGNETIC GUN BY GRADIENT MAGNETIC FIELD
}

\author{
A.S. Mazmanishvili, N.G. Reshetnyak, V.P. Romas'ko, I.A. Chertishchev \\ National Science Center “Kharkov Institute of Physics and Technology”, Kharkiv, Ukraine
}

The results of experimental studies and modeling calculations for controlling the transverse dimensions of an electron beam formed by a magnetron gun with a secondary emission cathode are presented. In the gun, the secondary emission process is launched by a voltage pulse with an amplitude of up to $15 \mathrm{kV}$ supplied to its anode. The dependence of the radial dimensions of the electron beam on the amplitude and gradient of the magnetic field in the transport channel is investigated. It is shown that the obtained experimental results are consistent with the simulation results. The possibility of adjusting the beam diameter by varying the configuration of the magnetic field is established. The experimental results presented indicate the possibility of realizing irradiation of the outer surface of cylindrical samples placed in the region of the gradient magnetic field.

PACS: 29.27.Fh

\section{INTRODUCTION}

The study of electron beams of various configurations and intensities is associated with their use in highvoltage pulsed microwave electronics, electron beam technologies of accelerator technology, etc. $[1,2]$. The use of the beam method of sample processing makes it possible to change the structural-phase states in the surface layers, to create materials with improved characteristics, increased micro hardness, corrosion resistance, etc. $[3,4]$. To solve these problems, electron accelerators with energy of $100 \ldots 400 \mathrm{keV}$ are widely used [5].

At the NSC KIPT, studies are conducted with electron sources with cold metal cathodes operating in the secondary emission mode from the surface of the cathodes in crossed electric and magnetic fields. An electron accelerator was created on the basis of a magnetron gun with a secondary emission cathode, in which an axial electron beam is used to irradiate metal targets $[4,5]$. In [6 - 8], the possibility of irradiating the inner cylindrical surface of a target using a radial electron beam was studied.

In this paper, we present the results of a study of the dependence of the radial dimensions of the electron beam on the amplitude and gradient of the magnetic field in the transportation channel and numerical simulation of the movement of the tubular electron beam. The possibility of controlling the transverse dimensions of the electron beam using a gradient magnetic field, which is created both by the $\mathrm{H}_{\mathrm{S}}$ solenoid and jointly by the $\mathrm{H}_{\mathrm{SM}}$ solenoid and permanent magnet, is studied.

The main objective of the research is the experimental study of the radial dynamics of electron flows in order to control the process of irradiation of the outer cylindrical surface of the samples in the transport channel.

\section{EXPERIMENTAL EQUIPMENT}

Studies were carried out on the formation of an electron beam and the measurement of its parameters during transportation in a gradient magnetic field. The installation block diagram is shown in Fig. 1.

To obtain an electron beam, a magnetron gun with a secondary emission cathode is used. Gun dimensions: cathode diameter $36 \mathrm{~mm}$, inner diameter of the anode $78 \mathrm{~mm}$, cathode length $80 \mathrm{~mm}$, anode $135 \mathrm{~mm}$. The cathode material is copper, the anode is stainless steel. The magnetron gun is placed in a vacuum volume (2) (pressure $10^{-6}$ Torr).

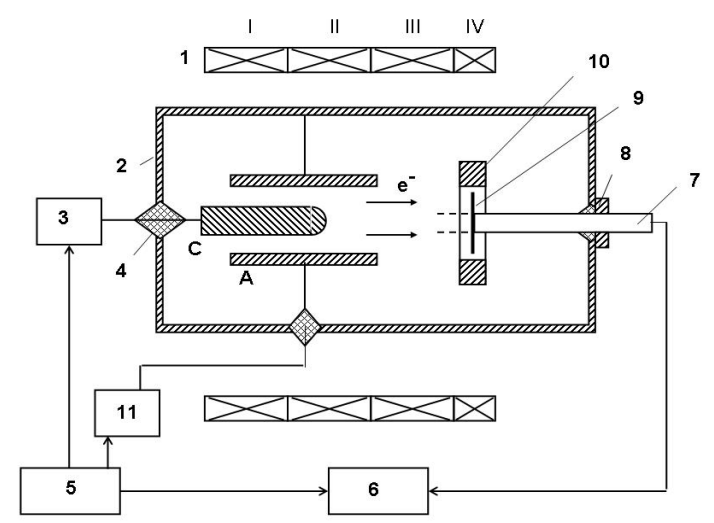

Fig. 1. The block diagram of the experimental setup. 1 - sections of the solenoid (I, II, III, IV); 2 - vacuum volume; 3 - high-voltage pulse generator; 4 -insulator; 5 - synchronization unit; 6 -computer measuring system; 7 - centering rod; 8-seal; 9 -Faraday cup; 10 - ring magnet; 11 - generator; $A$-anode; $C$-cathode

The secondary emission propagation in the gun is triggered by a voltage pulse with a steep drop, which is created by a voltage pulse from the generator (11) with an amplitude of up to $18 \mathrm{kV}$ supplied to the anode. To power the magnetron gun, a pulsed generator (3) was used with an amplitude of the flat part of the pulse $20 \ldots 100 \mathrm{kV}$, a duration of $50 \ldots 10 \mu \mathrm{s}$ and a repetition rate of $3 \ldots 10 \mathrm{~Hz}$, which is fed to the gun cathode. The generator circuit used a full discharge of the storage capacitance to the transformer through the thyratron. Secondary emission propagation in the gun is triggered by a voltage pulse with a steep drop supplied to the gun anode, which was created by the generator (8) with voltage amplitude of up to $15 \mathrm{kV}$. Electron source $(\mathrm{C}$ is the cathode, $\mathrm{A}$ is the anode) is placed in a vacuum volume (2). The magnetic field for generating and transporting the beam is created by a solenoid (1), consisting of 4 sections. The amplitude and longitudinal distribution of the magnetic field can be controlled by changing the magnitude of the currents in the coils of the solenoid. The Faraday cylinder (9) serves as a target and is located at a distance of $2 \ldots 15 \mathrm{~cm}$ from the anode section. To create an additional magnetic field, a permanent ring magnet (10) was used, located at a distance of $7 \mathrm{~cm}$ from the cut of the gun's anode. The transverse dimensions of the beam are measured by obtaining fingerprints on metal sensors installed at different distances from the cut of the anode. Processing the results of 
measurements of the beam current parameters from the Faraday cup and the voltage pulse is carried out using the measuring system (6).

\section{RESEARCH CHARACTERISTICS PERMANENT MAGNET}

The distribution of the longitudinal $\mathrm{H}_{\mathrm{z}}$ and radial $\mathrm{H}_{\mathrm{r}}$ components of the magnetic fields in a permanent magnet with an outer diameter of $100 \mathrm{~mm}$, an inner diameter of $60 \mathrm{~mm}$, and a thickness of $30 \mathrm{~mm}$ was measured. The longitudinal component of the magnetic field $\mathrm{H}_{\mathrm{z}}$ was measured at radii of $0,18,22$, and $24 \mathrm{~mm}$. The longitudinal component of the magnetic field (Fig. 2) varies from $\sim 0.15 \mathrm{~T}$ at radius $\mathrm{r}=0 \mathrm{~mm}$ to $\sim 0.3 \mathrm{~T}$ at radius $\mathrm{r} \sim 24 \mathrm{~mm}$.

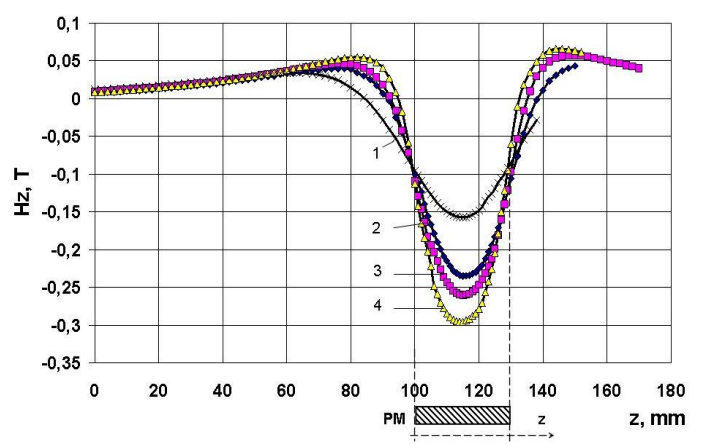

Fig. 2. The distribution of the radial magnetic field $H_{z}$ at various radii. $1-r=0 \mathrm{~mm} ; 2-r=18 \mathrm{~mm}$;

$3-r=22 \mathrm{~mm} ; 4-r=24 \mathrm{~mm}$. Scale: $0.05 \mathrm{~T} / \mathrm{unit}$

As can be seen from Fig. 2, the magnetic field at the edges of the magnet drops from $0.3 \mathrm{~T}$ to zero over a length of $\mathrm{z} \sim 20 \mathrm{~mm}$ and changes direction in the opposite direction with an amplitude of $\sim 0.05 \mathrm{~T}$. At a length of $\mathrm{z} 110 \mathrm{~mm}$ from the center of magnet, the amplitude is $\sim 0.008 \mathrm{~T}$.

A longitudinal $\mathrm{H}_{\mathrm{z}}$ field was measured in 16 directions at radii of $8,12,16,20$, and $24 \mathrm{~mm}$ in order to study the field uniformity. It is determined that the magnetic field is quite uniform in azimuth. The field heterogeneity in azimuth at a radius $\mathrm{r}=8 \mathrm{~mm}$ is $\sim 1 \%$, and at $\mathrm{r}=20 \mathrm{~mm} \leq 3 \%$.

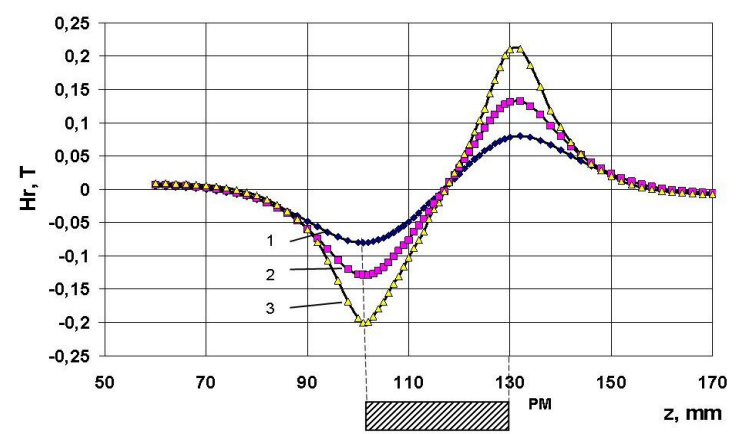

Fig. 3. The distribution of the radial magnetic field $H_{r}$ at various radii. $1-r=18 \mathrm{~mm} ; 2-r=22 \mathrm{~mm}$; $3-r=24 \mathrm{~mm}$. Scale: $0.05 \mathrm{~T} /$ unit

In Fig. 3 shows the distribution of the radial component of the magnetic field $\mathrm{H}_{\mathrm{r}}$ at various radii of 18,22 , $24 \mathrm{~mm}$. In this case, the radial component of the magnetic field is symmetric with respect to the center of the magnet. The maxima of the magnetic field at a radius of $\mathrm{r}=24 \mathrm{~mm}$ are located at the edges of the magnet and are $0.2 \mathrm{~T}$, and at a radius of $r=18 \mathrm{~mm}$ they decrease to $0.075 \mathrm{~T}$. The field decreases from the maximum to zero at a distance $z=25 \mathrm{~mm}$. The inhomogeneity of the radial $\mathrm{H}_{\mathrm{r}}$ component of the magnetic field is $\sim 5 \%$.

\section{EXPERIMENTAL RESULTS AND THEIR DISCUSSION}

Research was conducted on the formation of an electron beam and the measurement of their parameters under various configurations of magnetic fields at the cathode and in the beam transport channel. The experiments were conducted at a cathode voltage of $20 \ldots 80 \mathrm{kV}$. The dependence of the transverse dimensions of the electron beam on the configuration of the magnetic field in the electron flux transport channel is studied. Comparison is made with simulation data.

In Fig. 4 shows the distributions of the magnetic field $\mathrm{H}_{\mathrm{z}}$ along the axis of the magnetron gun and the beam transport channel, which were used in the research. Magnetic fields are created both by a solenoid $\left(\mathrm{H}_{\mathrm{S}}\right.$ - curves $\left.3-6\right)$, and together with a solenoid and a permanent magnet $\left(\mathrm{H}_{\mathrm{SM}}\right.$ - curves 1,2$)$. By adjusting the current in the solenoid coils, it is possible to create different distributions of $\mathrm{H}_{\mathrm{S}}$ magnetic fields both on the cathode and in the beam transport channel: increasing with a gradient of $0.030 \mathrm{~T} / \mathrm{cm}$ curve 3), uniform (curve 5), decreasing with a gradient of $0.060 \mathrm{~T} / \mathrm{cm}$ (curve 6). This made it possible to obtain various modes of electron beam formation.

The research results were recorded on metal targets for various configurations of the magnetic fields $\mathrm{H}_{S}$ and The research results were recorded on metal targets for various configurations of the magnetic fields $\mathrm{H}_{\mathrm{S}}$ and $\mathrm{H}_{\mathrm{SM}}$.

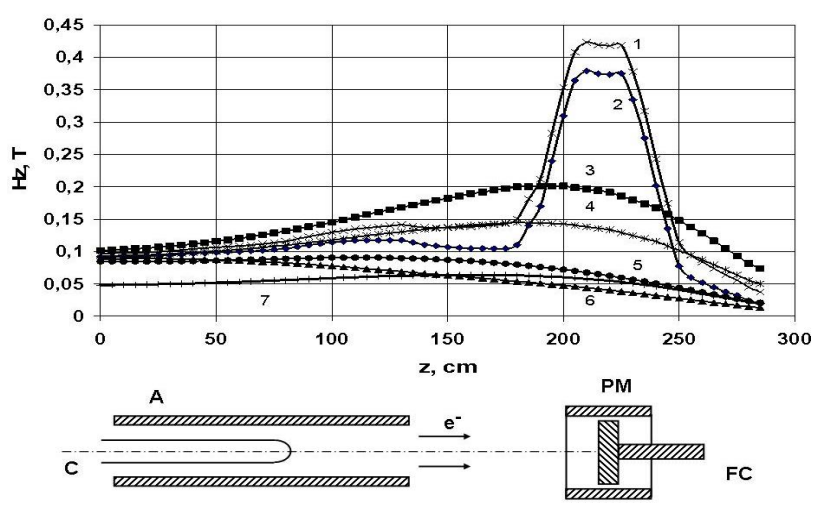

Fig. 4. The distribution of magnetic fields (curves 1 - 6) along the axis of the gun and the beam transport channel, the placement of the gun elements; $A$-anode; $C$-cathode; $P M$ - permanent magnet; $F C$ - Faraday cup (target)

Thus, fingerprints on the targets made it possible to interpret the dynamics of electron flows.

Fingerprints were received for the $H_{S}$ and $H_{S M}$ fields. The $\mathrm{H}_{\mathrm{SM}}$ field configuration is characterized by a significant positive gradient, and the $\mathrm{H}_{\mathrm{S}}$ field configuration is characterized by a small gradient behind the anode section (see Fig. 4). In our studies, for both magnetic field distributions $\mathrm{H}_{\mathrm{S}}$ and $\mathrm{H}_{\mathrm{SM}}$, a fairly good homogeneity of the azimuthally distribution of the electron beam current was obtained.

Figs. 5 and 6 show the main experimental data and the corresponding data of modeling calculations. 

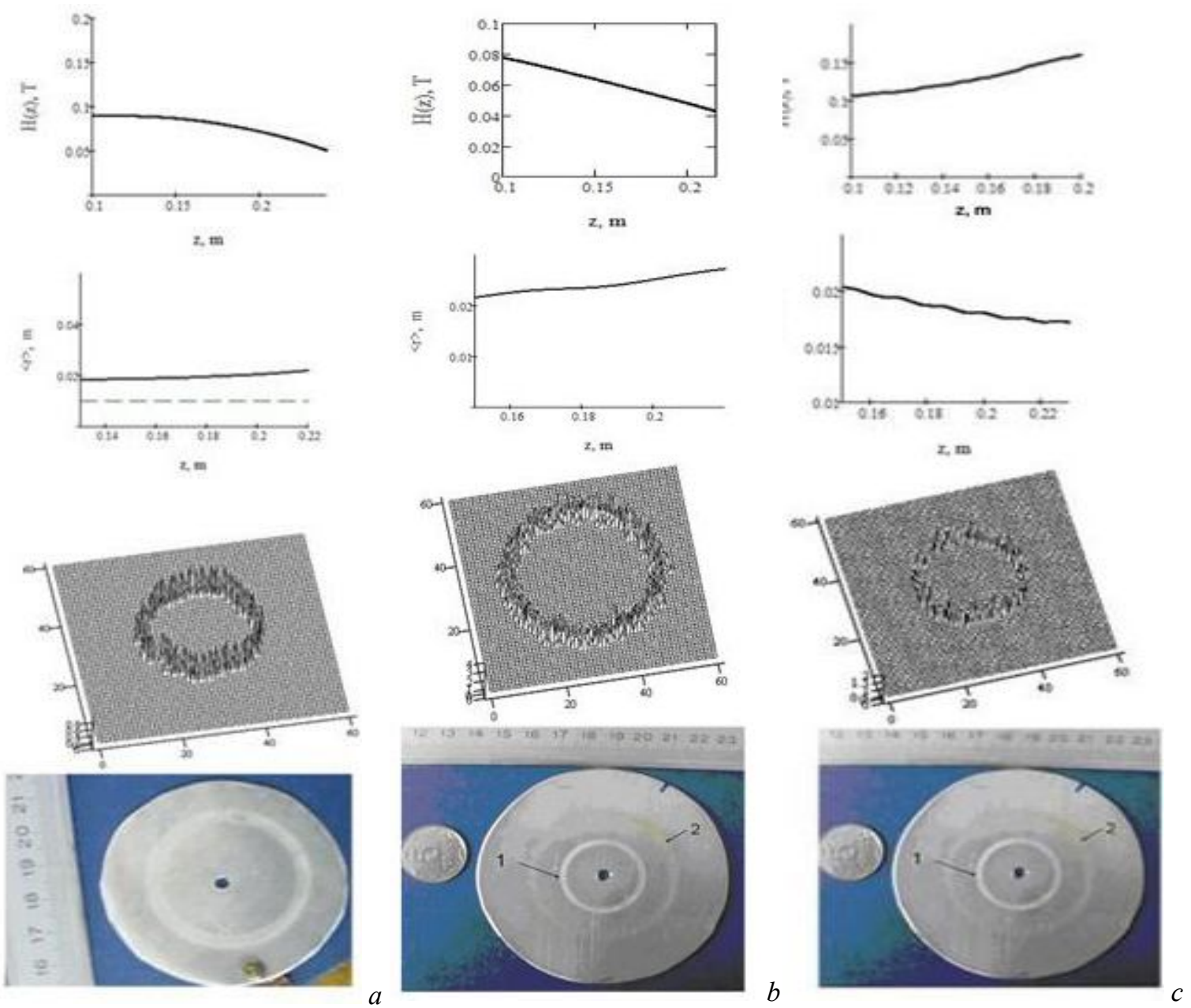

Fig. 5. The magnetic field configuration $H_{S}$, the dependence of the average radius $\langle r\rangle$ on the $z$ coordinate, the result of modeling the transverse distribution of the beam density at $z_{M}=165 \mathrm{~mm}(\mathrm{a})$ and $z_{M}=205 \mathrm{~mm}(\mathrm{~b}, \mathrm{c})$ and the imprint of the beam on the target

In Fig. 5 shows (top-down): the configuration of the solenoid magnetic field (the result of approximating the experimental data), the dependence of the average beam radius $\langle r\rangle$ on the longitudinal coordinate $z$ obtained in modeling calculations, the results of numerical simulation of the transverse distribution of particle density (image area $80 \times 80 \mathrm{~mm}$ ) and experimental prints of the electron beam on the targets. In Fig. 5,b,c, the fingerprints are shown at a reduced image scale, and in Fig. 5,a-with an enlarged scale.

Measurements of the sizes of the electron beam on the targets showed that at a voltage of $60 \mathrm{kV}$ at the cathode and a uniform magnetic field $\mathrm{H}_{\mathrm{S}}$, the magnetron gun forms an electron beam with an outer diameter of $D_{\mathrm{M}} \sim 40 \mathrm{~mm}$ and a wall thickness of $2 \mathrm{~mm}$ (see Fig. 5,a).
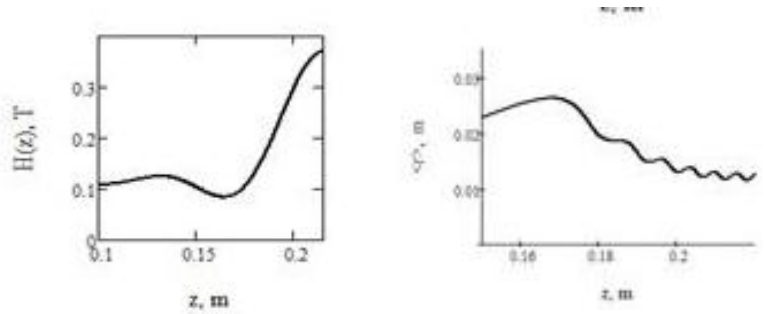

In a decreasing magnetic field $\mathrm{H}_{\mathrm{S}}$ in the beam transport region (see Fig. 5,b), the magnetron gun forms an electron beam with an outer diameter of $D_{\mathrm{M}}=48 \mathrm{~mm}$ and a wall thickness of $3 \mathrm{~mm}$ (curve 2). With an increasing magnetic field $\mathrm{H}_{\mathrm{S}}$ (see Fig. 5,c), the outer diameter of the beam decreased to $D_{\mathrm{M}} \sim 30 \mathrm{~mm}$ with a wall thickness of $1.5 \mathrm{~mm}$ (curve 1). The indicated values for the outer diameters of $D_{\mathrm{M}}$ correspond to the dependences of the average radius $\langle r\rangle$ shown in Fig. 5,a,b,c (second line).

When the electron beam moves in an increasing magnetic field, the $\mathrm{H}_{\mathrm{SM}}$ with a significant gradient of $\sim 0.1 \mathrm{~T} / \mathrm{cm}$ (see Fig. 6), the magnetron gun forms an electron beam with an outer diameter $D_{\mathrm{M}}=22 \mathrm{~mm}$ and a wall thickness of $1 \mathrm{~mm}$.
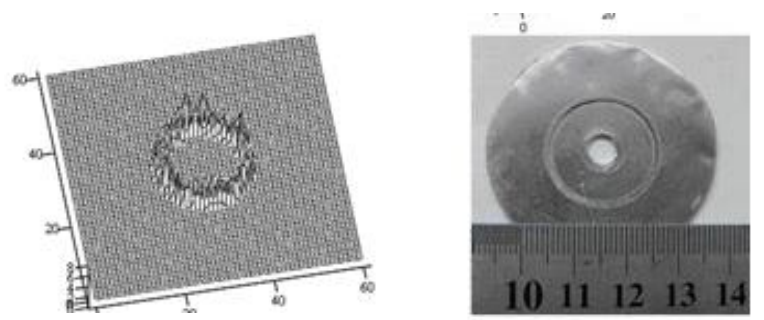

Fig. 6. (from left to right). $H_{S M}$ magnetic field configuration, mean radius $<r>$ versus $z$ coordinate, the calculated transverse distribution of the beam density at $z_{M}=0,205 \mathrm{~m}$ and the imprint of the beam on the target 

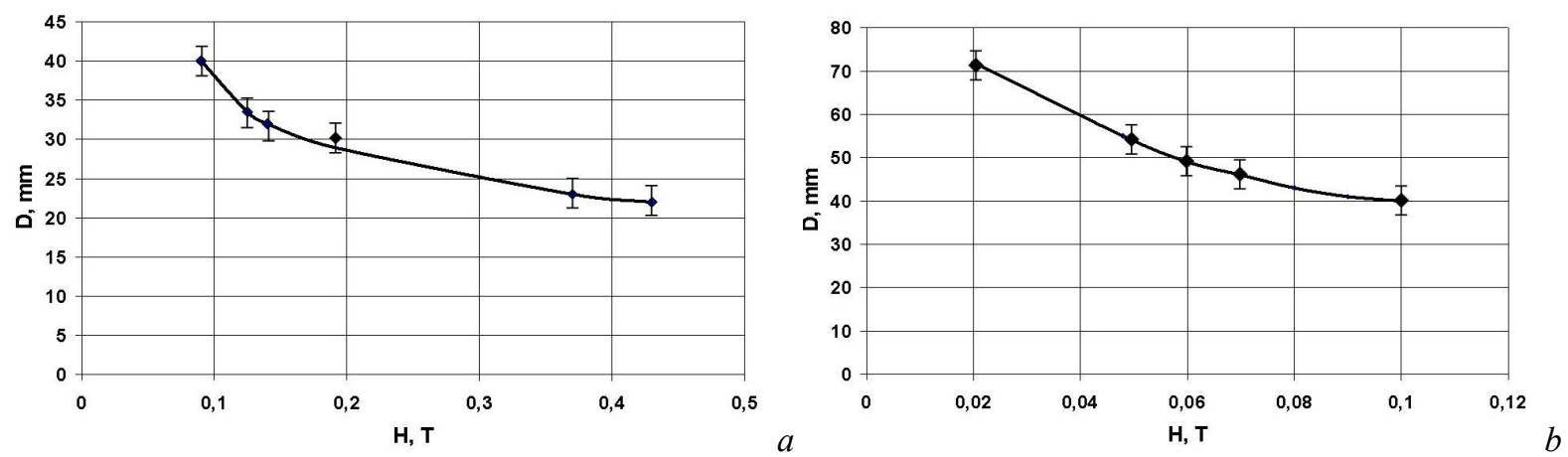

Fig. 7. The dependence of the diameter of the electron beam on the amplitude of the magnetic field at a distance of $z=75 \mathrm{~mm}\left(\right.$ a) and $z=125 \mathrm{~mm}$ (b) from the gun cut for the magnetic field configurations $H_{S}$ and $H_{S M}$; $a$-increasing magnetic field; $b$-decreasing magnetic field

When the electron beam moves in a decreasing magnetic field $\mathrm{H}_{\mathrm{S}}$ (Fig. 7,b) with a gradient of $\sim 0,01 \mathrm{~T} / \mathrm{cm}$ and magnetic field amplitude of $0.02 \mathrm{~T}$, a noticeable increase in the beam diameter occurs.

In Fig. 7 shows the dependence of the diameter of the electron beam on the amplitude of the magnetic field for the magnetic field configurations $\mathrm{H}_{\mathrm{S}}$ and $\mathrm{H}_{\mathrm{SM}}$.

From Fig. 7,a it is seen that with an increase in the $\mathrm{H}_{\mathrm{S}}$ amplitude when the electron beam moves in an increasing magnetic field of the $\mathrm{H}_{\mathrm{SM}}$ with a gradient of $0.1 \mathrm{~T} / \mathrm{cm}$ and magnetic fields of $\sim 0.4 \mathrm{~T}$ a substantial decrease in the diameter of the electron beam occurs. When the electron beam moves in a decreasing magnetic field $\mathrm{H}_{\mathrm{S}}$ (see Fig. 7,b) with gradient of $\sim 0.01 \mathrm{~T} / \mathrm{cm}$ and magnetic field amplitude of $0.02 \mathrm{~T}$, a noticeable increase in the beam diameter occurs.

From the above data it follows the possibility of irradiating the outer surface of cylindrical samples placed in the region of the gradient magnetic field, the scheme of which is shown in Fig. 8 .

The obtained experimental results show that when cylindrical samples are placed in a region with a significant positive magnetic field gradient, the diameter of the electron beam decreases. As a result, the outer surface of the cylindrical samples will be irradiated.

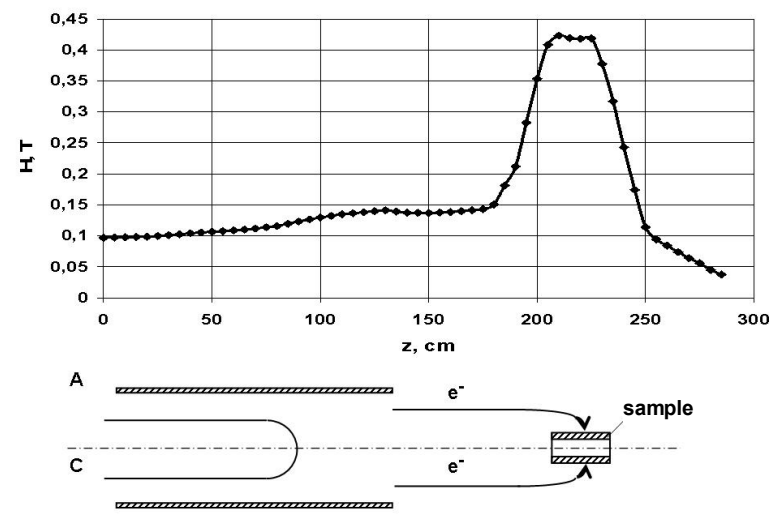

Fig. 8. Scheme of irradiation of the outer surface of cylindrical samples with an electron beam in an increasing gradient magnetic field

\section{CONCLUSIONS}

From the above studies it follows that the electron flux at the exit of the magnetron gun experiences a rearrangement of the radial distribution, which is determined by the form of the gradient magnetic field in the beam transport channel. The possibility of adjusting the beam diameter by varying the magnetic field is shown. It is shown that the obtained experimental data are consistent with the simulation results. The experimental results presented indicate the possibility of realizing irradiation of the outer surface of cylindrical samples placed in the region of the gradient magnetic field.

\section{REFERENCES}

1. V.I. Engelko, G. Mueller, A. Andreev, et al. Pulsed Electron Beam Facilities (GESA) for Surface Treatment // Proc. of $10^{\text {th }}$ International Conf. on Applied Charged Particle Accelerators in Medicine and Industry. St.-Petersburg, Russia, 2001, p. 412-417.

2. M.F. Vorogushin, V.A. Glukhikh, G.S. Manukyan, D.A. Karpov, M.P. Svin'in, V.I. Ehngelko, B.P. Yatsenko. Beam and ion-plasma technologies // Problems of Atomic Science and Technology. Series "Physics of Radiation Effects and Radiation Materials Science”. 2002, № 3, p. 101-109.

3. V.A. Glukhikh, O.P. Pechersky, V.I. Engelko, B.P. Yatsenko. Modification of surface properties of materials using powerful pulsed electron beams // Reports of the X International Meeting on the Use of Charged Particle Accelerators in Industry and Medicine. St. Petersburg, 2001, p. 445-447.

4. A.N. Dovbnya, S.D. Lavrinenko, V.V. Zakutin, et al. Surface modification of zirconium and $\mathrm{Zr} 1 \% \mathrm{Nb}$ alloy by the electron beam of the magnetron gunbased accelerator // Problems of Atomic Science and Technology. Series "Physics of Radiation Effects and Radiation Materials Science”. 2011, № 2, p. 39-45.

5. O.V. Garkusha, S.P. Maslennikov, A.E. Novozhilov, E.Ya. Shkol'nikov. A high-current accelerator of microsecond electrons for radiation-technological purposes // Proc. of the XI International Meeting on the Use Charged Particle Accelerators in Industry and Medicine. St.-Petersburg, Russia, 2005, p. 118-121.

6. A.N. Dovbnya, V.V. Zakutin, N.G. Reshetnyak, et al. Investigation of beam formation in an electron accelerator with a secondary-emission source // Journal of Kharkiv National University. Physical Series "Nuclear, Particle, Fields" 2006, № 732, v. 2(30), p. 96-100.

7. M.I. Ayzatsky, A.N. Dovbnya, A.S. Mazmanishvili, N.G. Reshetnyak, V.P. Romas'ko, I.A. Chertishchev. Studies on formation of the radially-directed electron beam generated by the magnetron gun with a 
secondary emission cathode // Problems of Atomic Science and Technology. Series "Nuclear Physics Investigations”. 2016, № 3, p. 11-16.

8. A.N. Dovbnya, N.A. Dovbnya, A.S. Mazmanishvili, N.G. Reshetnyak, I.A. Chertishchev. Transport simulation of a high-current electron beam formed by the magnetron gun with a secondary-emission cathode in a decreasing solenoid field // Problems of Atomic Science and Technology. Series "Nuclear Physics Investigations”. 2015, № 6, p. 77-82.

Article received 11.12.2019

\section{УПРАВЛЕНИЕ ПОПЕРЕЧНЫМИ РАЗМЕРАМИ ЭЛЕКТРОННОГО ПУЧКА НА ВЫХОДЕ МАГНЕТРОННОЙ ПУШКИ С ПОМОЩЬЮ ГРАДИЕНТНОГО МАГНИТНОГО ПОЛЯ}

\section{А.С. Мазманишвили, Н.Г. Решетняк, В.П. Ромасько, И.А. Чертищев}

Представлены результаты экспериментальных исследований и моделирующих расчетов по управлению поперечными размерами электронного пучка, формируемого магнетронной пушкой с вторичноэмиссионным катодом. В пушке запуск вторично-эмиссионного процесса осуществляется импульсом напряжения амплитудой до 15 кВ, подаваемым на её анод. Исследована зависимость радиальных размеров электронного пучка от амплитуды и градиента магнитного поля в канале транспортировки. Показано, что полученные экспериментальные результаты согласуются с результатами моделирования. Установлена возможность регулировки диаметра пучка путем вариации конфигурации магнитного поля. Указана возможность облучать наружную поверхность цилиндрических образцов, помещенных в область градиентного магнитного поля.

\section{УПРАВЛІННЯ ПОПЕРЕЧНИМИ РОЗМІРАМИ ЕЛЕКТРОННОГО ПУЧКА НА ВИХОДІ МАГНЕТРОННОӤ ГАРМАТИ ЗА ДОПОМОГОЮ ГРАДІЕНТНОГО МАГНІТНОГО ПОЛЯ}

\section{О.С. Мазманишвілі, М.Г. Решетняк, В.П. Ромасько, І.О. Чертіщев}

Представлено результати експериментальних досліджень і моделюючих розрахунків з управління поперечними розмірами електронного пучка, що формується магнетронною гарматою з вторинно-емісійним катодом. У гарматі запуск вторинно-емісійного процесу виконується імпульсом напруги амплітудою до 15 кВ, що подається на ï анод. Досліджена залежність радіальних розмірів електронного пучка від амплітуди та градієнта магнітного поля в каналі транспортування. Показано, що отримані експериментальні результати узгоджуються 3 результатами моделювання. Встановлена можливість регулювання діаметра пучка шляхом варіації конфігурації магнітного поля. Вказана можливість опромінювати зовнішню поверхню циліндричних зразків, що розташовані в області градієнтного магнітного поля. 